\title{
Prototype Pengadaan Dan Distribusi Barang Pada Waralaba Fried Chicken dan Burger lampung
}

\author{
Dona Yuliawati ${ }^{1}$, Sushanty Saleh ${ }^{2}$, Indera ${ }^{3}$ \\ ${ }^{1}$ Program Studi Sistem Informasi Institut Informatika dan Bisnis Darmajaya \\ ${ }^{2}$ Program Studi Sistem Informasi Institut Informatika dan Bisnis Darmajaya \\ ${ }^{3}$ Program Studi Sistem Informasi Institut Informatika dan Bisnis Darmajaya \\ ${ }^{1}$ donayuliawati@gmail.com \\ ${ }^{2}$ schanty2000@gmail.com \\ 3indera@gmail.com
}

\begin{abstract}
Based on the research data, it is that the leader of Master Fried Chicken and Burger have difficulties about stock and good distribution activities as delayof stock and goods distribution, hoarding goods in warehouse, file duplication, hard file finding, information given are not accurate and takes long time in searching the data as it has no reports provided to leaders even in stock reports or in goods distribution report. The method used in this research is orientasi design analysis with the use of UML model using Netbeans IDE 6.0. tools and to make Master Fried Chicken and Burger needs stock and goods distributions system which are developed to be a program using java programming language. The system made can report which are not existed before like goods data report. Kiosk data, staff data and supplier data. Bisedes, this system can print road letter, purchasing application letter, report of stock and goods distribution perkioask per period faster by inputting number or period of printed date. By using this stock and goods distribution, it is expected to help Master Fried Chiken and Burger in controlling its stock and goods distribution.
\end{abstract}

Keywords: Procurement; Distribution of goods; UML

\begin{abstract}
Abstrak
Perusahaan Master Fried Chicken And Burger Bandar Lampung mengolah dan menjual produk berupa ayam goreng dan burger yang merupakan usaha waralaba yang telah memiliki empat belas outlet di wilayah Bandar Lampung, tiga outlet di luar kota Bandar Lampung dan tiga outlet di Kota Palembang. Telah didapatkan data melalui penelitian di Master Fried Chicken And Burger bahwa pimpinan mengalami beberapa kesulitan dalam perusahaan mengenai kegiatan pengadaan dan distribusi barang, seperti kegiatan pengadaan dan distribusi barang yang sering tertunda, terjadinya penumpukan barang di gudang, terjadinya duplikasi file, sulitnya pencarian file, informasi yang diberikan kurang akurat dan membutuhkan waktu yang cukup lama dalam pencarian data serta belum adanya laporan yang disajikan untuk pimpinan, baik laporan pengadaan maupun laporan distribusi barang. Metode yang digunakan adalah analisis desain berorientasi objek dengan pemanfaatan pemodelan $U M L$ menggunakan tools NetBeans IDE 6.0, dan untuk memudahkan pihak Master Fried Chicken And Burger dalam menentukan pengadaan dan distribusi barang, maka Master Fried Chicken And Burger membutuhkan sistem pengadaan dan sistem distribusi barang yang kemudian dikembangkan menjadi suatu program dengan menggunakan bahasa pemrograman java. Sistem yang dibuat dapat menghasilkan laporan-laporan yang sebelumnya belum ada, seperti laporan data barang, data kios, data petugas, dan data supplier. Selain itu dengan sistem ini dapat mencetak surat jalan, surat permohonan pembelian, laporan pengadaan barang dan laporan distribusi barang perkios perperiode dengan cepat. Diharapkan dengan adanya sistem pengadaan dan distribusi barang ini dapat membantu bagi pihak Master Fried Chicken And Burger dalam mengendalikan pengadaan barang dan distribusinya.
\end{abstract}

Kata Kunci: Pengadaan; Distribusi Barang; $U M L$ 


\section{PENDAHULUAN}

Semakin kompleksnya permasalahan hidup manusia, menuntut teknologi sebagai salah satu sarana yang membantu dalam menyelesaikan pekerjaan manusia. Diantara teknologi yang ada saat ini, teknologi komputer mengalami perkembangan yang sangat pesat. Pengolahan data melalui alat bantu komputer dapat memungkinkan tercapainya suatu informasi yang lebih cepat dan akurat. Perusahaan Master Fried Chicken And Burger Bandar Lampung, mengolah dan menjual produk berupa ayam goreng dan burger. Usaha inimerupakanusaha waralaba yang telah memiliki empat belas kios di wilayah Bandar Lampung, tiga kios di luar kota Bandar Lampung dan tiga kios di Kota Palembang.

Dengan semakin banyaknya jumlah kios Master Fried Chicken And Burger, semakin banyak pula jumlah kebutuhan barang-barang yang harus dipenuhi untuk setiap kiosnya. Maka timbul beberapa permasalahan dalam perusahaan, diantaranya kegiatan pengadaan dan distribusi barang yang sering tertunda, terjadinya penumpukan barang di gudang, terjadinya duplikasi file, sulitnya pencarian file dan belum adanya laporan yang disajikan untuk manajer, baik laporan pengadaan maupun distribusi barang. Agar tertib administrasi maka diperlukan pengaturan dalam rangka kegiatan pengadaan dan distribusi barang yang dibutuhkan. Dengan sistem informasi yang lebih baik maka diharapkan dapat menunjang kemajuan bagi perusahaan. Untuk itu perlu adanya pengembangan sistem yang dapat mengurangi kesalahan yaitu dengan informasi yang berbasis komputer menggunakan bahasa pemrograman.

\section{KERANGKA TEORI}

\subsection{Teori Umum Pengembangan Sistem}

Metodologi analisis berorientasi objek adalah metode analisis yang memeriksa syarat-syarat dari sudut pandang kelas-kelas dan objek-objek yang ditemui pada ruang lingkup permasalahan dengan tujuan untuk memahami domain masalah dan meningkatkan ketelitian, konsistensi, kelengkapan analisis. Alat yang digunakan dalam metodologi ini salah satunya adalah $U M L$. Menurut Pilone, $U M L$ adalah alat komunikasi yang konsisten dalam mendukung para pengembang sistem saat ini(Pudjo Prabowo Widodo dan Herlawati, 2011).

Dalam proses iteratif, pengembang melakukan beberapa langkah berulang-ulang dan setiap waktu berfokus pada bagian-bagian yang berbeda dari sistem. Tahapan yang umum dilakukan dalam pengembangan perangkat lunak adalah sebagai berikut. (Nugroho Adi, 2005).
a. Pemodelan Bisnis.
b. Pemodelan Use-Case.
c. Analisis.
d. Perancangan.
e. Implementasi.

Agar dapat melakukan langkah-langkah sesuai dengan metodologi pengembangan analisis dan desain berorientasi objek, maka dibutuhkan alat dan teknik untuk melaksanakannya. Adapun alat pengembangan sistem yang digunakan yaitu sebagai berikut.

\section{a. Use Case Diagram}

Menurut Pilone, (Pudjo Widodo, Prabowo dan Herlawati. 2011. Menggunakan UML. Andi Ofset : Bandung) use case menggambarkan fungsi tertentu dalam suatu sistem berupa komponen, kejadian atau kelas. Use case 
diartikan sebagai urutan langkah-langkah yang secara tindakan saling terkait (skenario), baik terotomatisasi maupun secara manual, untuk tujuan melengkapi satu tugas bisnis tunggal. Diagram use case bersifat statis, diagram ini memperlihatkan himpunan use-case dan aktor-aktor (suatu jenis khusus dari kelas). Diagram ini terutama sangat penting untuk mengorganisasi dan memodelkan prilaku suatu sistem yang dibutuhkan serta diharapkan pengguna. Penjelasan simbol pada tabel 1

Tabel 1 Bagan Use Case Diagram

\begin{tabular}{|c|c|}
\hline SIMBOL & KETERANGAN \\
\hline$\rho^{\text {ACTOR }}$ & $\begin{array}{l}\text { Mendefinisikan entitas diluar } \\
\text { sistem yang memakai sistem. }\end{array}$ \\
\hline USE CASE & $\begin{array}{l}\text { Gambaran fungsinalitas dari suatu } \\
\text { sistem, sehingga pengguna } \\
\text { mengerti kegunaan sistem yang } \\
\text { akan dibangun }\end{array}$ \\
\hline RELASI & $\begin{array}{l}\text { Menceritakan hubungan antara } \\
\text { aktor dan use case sehingga } \\
\text { diagram dapat dipahami }\end{array}$ \\
\hline
\end{tabular}

\section{b. Activity Diagram}

Aktivitas merupakan kumpulan aksi- aksi. Aksi-aksi melakukan langkah sekali saja tidak boleh dipecah menjadi beberapa langkah lagi. Sebagai contoh fungsi matematika, pemanggilan prilaku, pemrosesan data. Aktivitas dapat mengakses atribut dan operasi dan operasi classifier, tiap objek yang terhubung dan parameter-parameter jika aktivitas memiliki hubungan dengan prilaku. Ketika digunakan untuk model proses bisnis, informasi itu biasanya disebut procces-relevant data. Penjelasan bagan activity diagram dapat dilihat pada tabel 2

Tabel 2 Bagan Activity Diagram

\begin{tabular}{|l|l|}
\hline SIMBOL & \multicolumn{1}{|c|}{ KETERANGAN } \\
\hline PARTITION & $\begin{array}{l}\text { Memperlihatkan dimana aliran } \\
\text { berawal }\end{array}$ \\
\hline DELASI & $\begin{array}{l}\text { Merupakan langkah atau aksi- } \\
\text { aksi yang terjadi }\end{array}$ \\
\hline FORK & $\begin{array}{l}\text { Memperlihatkan dimana } \\
\text { keputusan perlu diambil selama } \\
\text { terjadi selama terjadi aliran kerja }\end{array}$ \\
\hline FINAL NODE & $\begin{array}{l}\text { Merupakan percabangan dari } \\
\text { sebuah aksi-aksi yang terjadi }\end{array}$ \\
\hline
\end{tabular}




\section{c. Sequence Diagram}

Sequence diagram menjelaskan interaksi objek yang disusun dalam suatu urutan waktu. Diagram ini secara Khusus berasosiasi dengan use case. Sequence Diagram memperlihatkan tahap demi tahap apa yang sebenarnya terjadi untuk menghasilkan sesuatu didalam use case. Penjelasan sequence diagram dapat dilihat pada tabel 3.

Tabel 3 Bagan Sequence Diagram

\begin{tabular}{|c|c|}
\hline SIMBOL & KETERANGAN \\
\hline$\overbrace{}^{\text {ACTOR }}$ & $\begin{array}{l}\text { Prilaku didalam } \\
\text { sequence Diagram }\end{array}$ \\
\hline OBJECT & \multirow[t]{2}{*}{$\begin{array}{l}\text { Menambahkan Objek } \\
\text { baru pada diagram }\end{array}$} \\
\hline & \\
\hline
\end{tabular}

\section{d. Collaboration Diagram}

Kolaborasi menggambarkan komunikasi antar objek. Kolaborasi yang digambarkan identik dengan kelas yang memiliki objek dan prilaku (Pudjo Widodo, Prabowo dan Herlawati. 2011. Menggunakan UML. Andi Ofset : Bandung). Dari pengertian diatas dapat diartikan bahwa Collaboration Diagram merupakan digram yang mengelompokan pesan pada kumpulan diagram sekuen menjadi sebuah diagram. Didalam diagram tersebut terdapat method yang dijalankan antara objek yang satu dengan objek yang lainya. Penjelasan collaboration diagram dapat dilihat pada tabel 4

Tabel 4 Collaboration Diagram

\begin{tabular}{|l|l|}
\hline SIMBOL & \multicolumn{1}{|c|}{ KETERANGAN } \\
\hline ACTOR & $\begin{array}{l}\text { Pelaku dalam collaboration } \\
\text { diagram }\end{array}$ \\
\hline OBJECT LINK & $\begin{array}{l}\text { Menambahkan instantiasi kelas } \\
\text { baru pada diagram }\end{array}$ \\
\hline LINK MESSAGE & Menciptakan lintasan komunikasi \\
\hline & antar dua objek \\
\hline & Menambahkan pesan antar dua \\
& objek ke dirinya sendiri \\
\hline
\end{tabular}




\section{e. Class Diagram}

Class Digram bersifat statis.Diagram ini memperlihatkan himpunan kelas-kelas, antarmuka-antarmuka, kolaborasi-kolaborasi, serta relasi-relasi. Diagram ini umum dijumpai pada pemodelan sistem berorientasi objek. Meskipun bersifat statis, sering pula diagram kelas memuat kelas-kelas aktif. Penjelasan simbol class diagram pada tabel 5

Tabel 5 Bagan Class Diagram

\begin{tabular}{|c|c|}
\hline Generalization & $\begin{array}{l}\text { Menggambarkan relasi } \\
\text { generalisasi }\end{array}$ \\
\hline Realize & $\begin{array}{l}\text { Menggambarkan relasi } \\
\text { realisasi }\end{array}$ \\
\hline Interface & $\begin{array}{l}\text { Menambahkan kelas } \\
\text { antarmuka } \\
\text { (interface) pada diagram }\end{array}$ \\
\hline Return message & $\begin{array}{l}\text { Menggambarkan } \\
\text { pengembalian dari } \\
\text { pemanggilan prosedur }\end{array}$ \\
\hline Aggregation & $\begin{array}{l}\text { Menggambarkan relasi } \\
\text { agregasi }\end{array}$ \\
\hline ACTOR & $\begin{array}{l}\text { Menggambarkan aktor } \\
\text { pada diagram } \\
\text { Kelas }\end{array}$ \\
\hline Boundary & $\begin{array}{l}\text { Menambahkan kelas } \\
\text { batasan } \\
\text { (boundary) pada diagram }\end{array}$ \\
\hline
\end{tabular}

\section{METODOLOGI}

\section{Tahapan Analisis Sistem}

Pada tahap ini dilakukan analisis dari sistem yang ada pada Master Fried Chicken And Burger Bandar Lampung, yaitu mengenai analisis sistem yang berjalan dan kelemahan dari sebuah sistem.

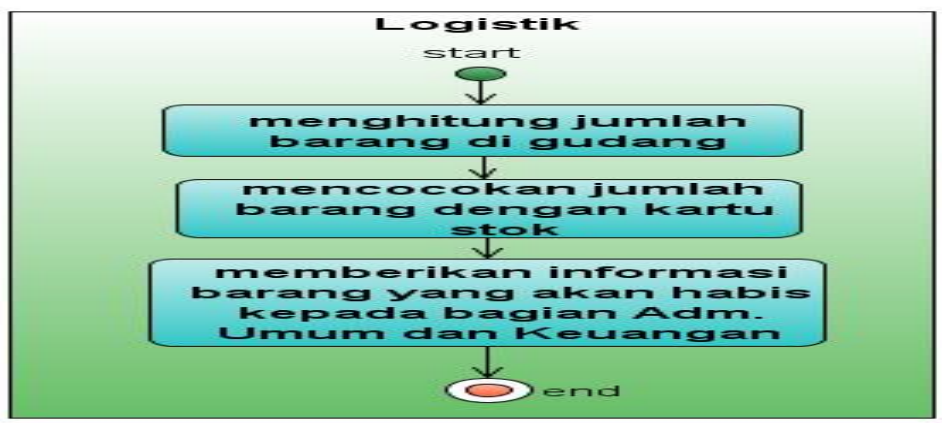

Gambar 1 Activity Diagram Pengecekan Stok Barang 


\subsubsection{Activity Diagram Pengecekan Stok Barang}

\subsubsection{Use Case Diagram Subsistem Distribusi Barang Yang Berjalan}

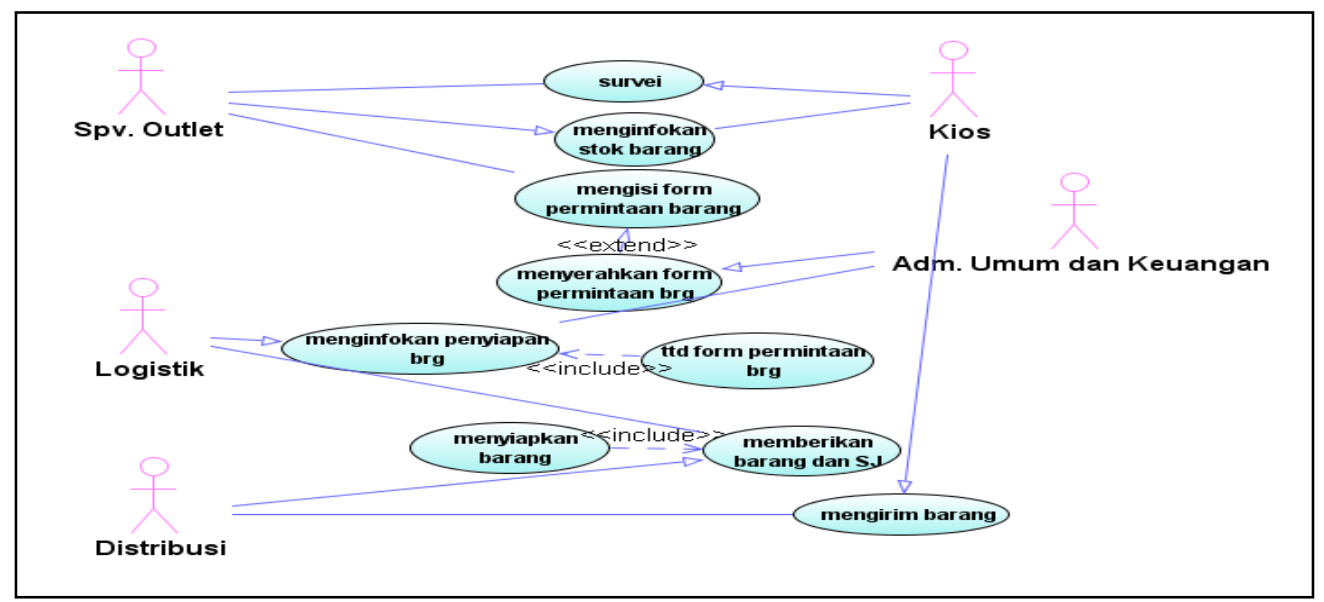

Gambar 2 Use Case Subsistem Distribusi Barang

\subsection{Kelemahan Sistem Pengolahan Saat ini}

Setelah dilakukannya analisis pada sistem pengolahan data pengadaan dan distribusi barang pada Master Fried Chicken And Burger Bandar Lampung terdapat beberapa kelemahan pada sistem tersebut antara lain :

a. Pada bagian Adm. Umum dan keuangan belum terdapat media yang dapat menyimpan data pengadaan dan distribusi barang, karena penyimpanan data hanya sebatas mengarsipkan form-form permintaan barang dan kwitansi pembelian barang.

b. Sering terjadi keterlambatan dalam proses pengadaan barang karena sering kali bagian logistik lalai dalam memberikan informasi mengenai stok barang ke bagian Adm. Umum dan Keuangan. Hal ini dikarenakan tidak adanya sistem yang dapat menunjang dalam mengetahui stok barang di gudang.

c. Bagian Adm. Umum dan keuangan sering mengalami kesulitan dalam proses pencarian data barang masuk dan barang keluar dikarenakan harus mencari berdasarkan arsip yang ada sehingga menyebabkan terhambat dalam pemrosesan data.

\section{HASIL DAN PEMBAHASAN}

\subsection{Analisis Sistem}

\subsection{Use Case Diagram Subsistem Pengadaan Barang Yang Diusulkan}

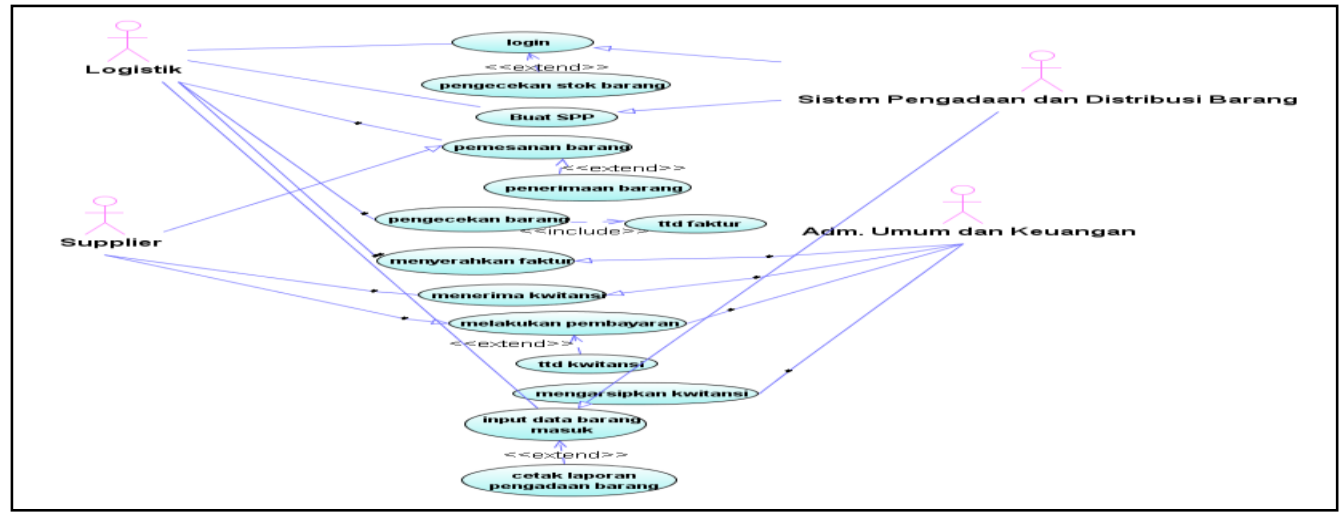

Gambar 3 Use Case Diagram Subsistem Pengadaan Barang yang diusulkan 


\subsubsection{Desain Use Case Subsistem Pengadaan Barang Yang Diusulkan}

\section{Nama Use Case : Login}

Actor $\quad$ : Bagian Logistik

Type : Primary Key

Tujuan : mengunakan sistem pengadaan dan distribusi barang

Deskripsi :Jika bagian logistik ingin menggunakan sistem pengadaan dan distribusi barang, maka bagian logistik harus login terlebih dahulu dengan memasukkan username dan password yang telah ditentukan. Jika username dan password yang dimasukkan benar atau valid maka bagian logistik dapat memilih menu sistem pengadaan dan distribusi barang yang telah tersedia untuk melakukan pengecekan stok barang. Penjelasan seperti tabel 6.

Tabel 6 Penjelasan Use Case Login

\begin{tabular}{|l|l|}
\hline \multicolumn{1}{|c|}{ LOGISTIK } & SISTEM \\
\hline $\begin{array}{l}\text { 1. Menjalankan sistem pengadaan dan } \\
\text { distribusi barang }\end{array}$ & \\
\hline & 2. Menampilkan menu login \\
\hline 3. Memasukan username dan password & \\
\hline & $\begin{array}{l}\text { 4. Menampilkan halaman utama sistem } \\
\text { pengadaan dan distribusi barang }\end{array}$ \\
\hline 5. Memilih menu data barang & \\
\hline
\end{tabular}

\subsection{Use Case Diagram Subsistem Pengadaan Barang Yang Diusulkan}

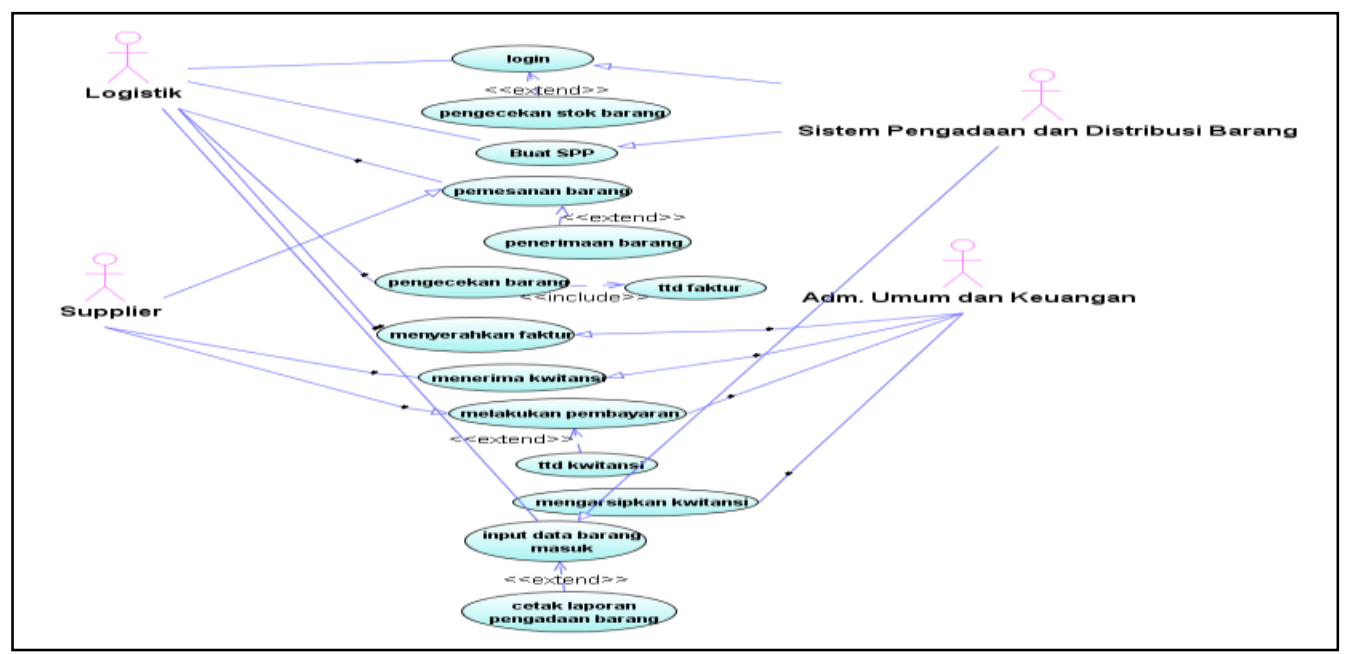

Gambar 4 Use Case Diagram Subsistem Pengadaan Barang yang diusulkan 


\subsection{Activity Diagram Pengecekan Stok Barang}

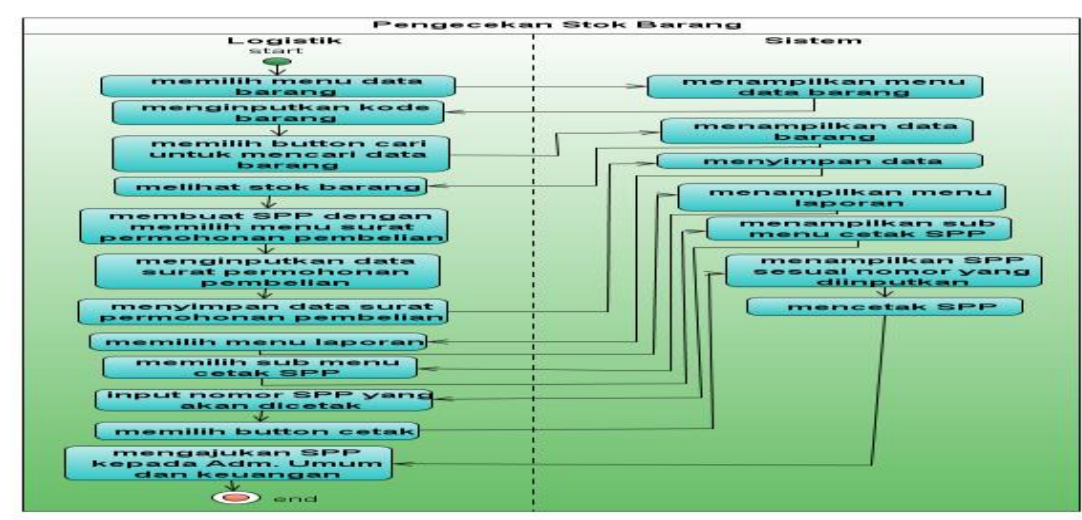

Gambar 5 Activity Diagram Pengecekan Stok Barang

\subsection{Activity Diagram Pemesanan Barang}

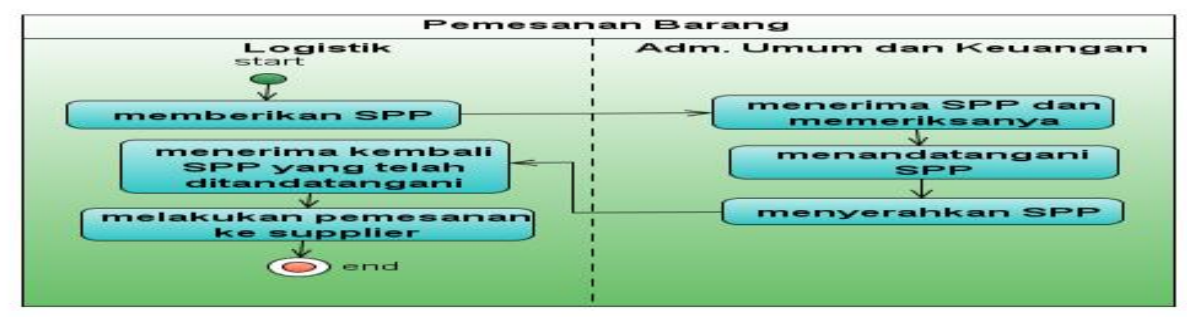

Gambar 6 Activity Diagram Pemesanan Barang

\subsection{Activity Diagram Penerimaan Barang}

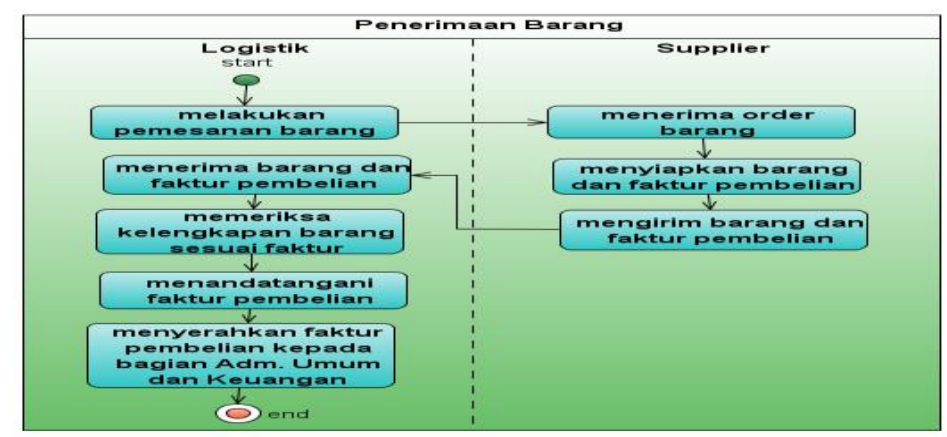

Gambar 7 Activity Diagram Penerimaan Barang

\subsection{Activity Diagram Melakukan Pembayaran}

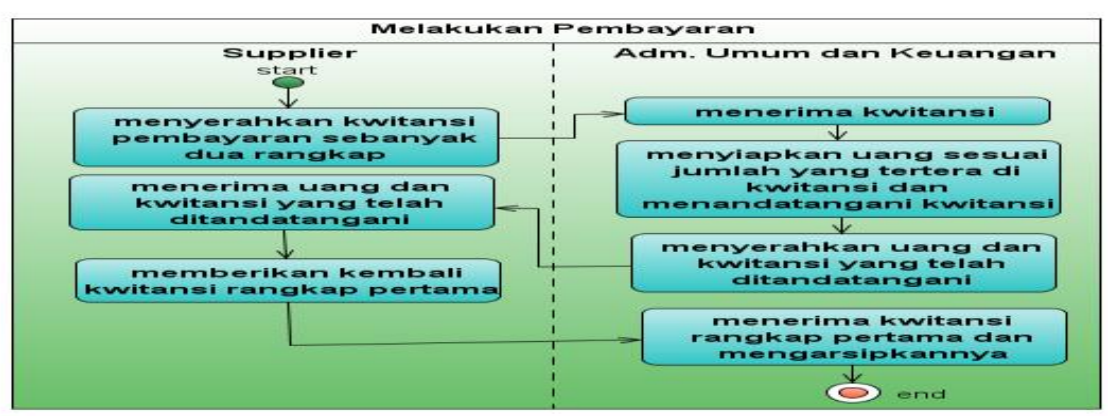

Gambar 8 Activity Diagram Melakukan Pembayaran 


\subsection{Activity Diagram Cetak Laporan Pengadaan Barang}

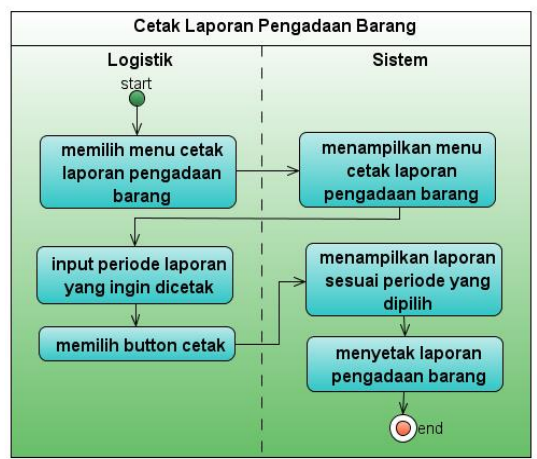

Gambar 9 Activity Diagram Cetak Laporan Pengadaan Barang

\subsection{Sequence Diagram Pengecekan Stok Barang}

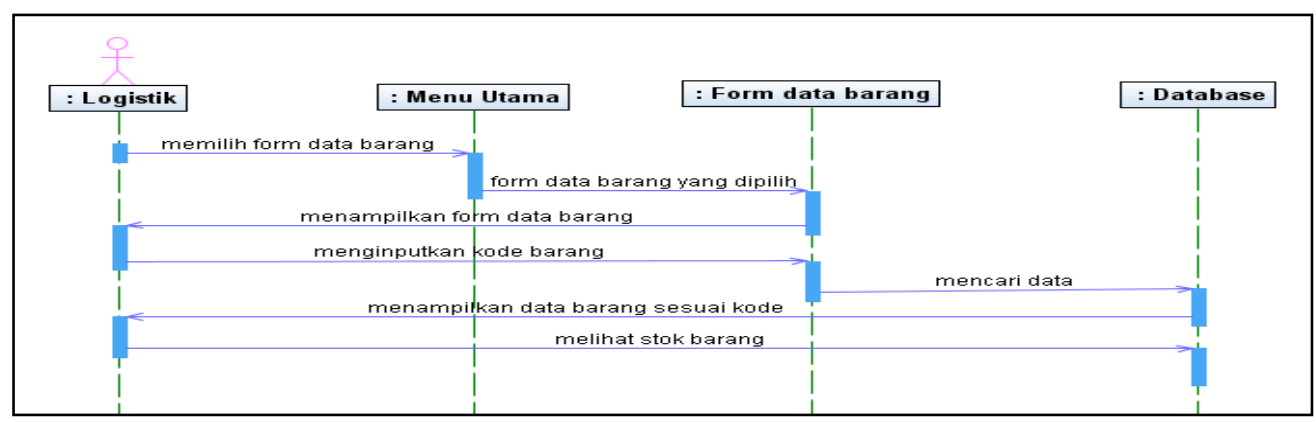

Gambar 10 Sequence Diagram Pengecekan Stok Barang

\subsection{Sequence Diagram Input Surat Permohonan Pembelian}

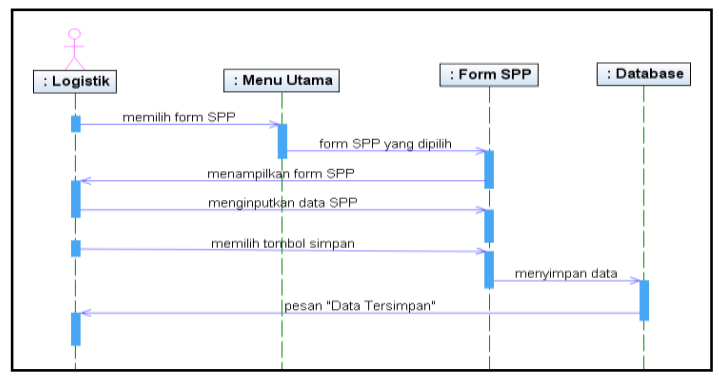

Gambar 11 Sequence DiagramInput Surat Permohonan Pembelian

\subsection{Sequence Diagram Input Data Barang Masuk}

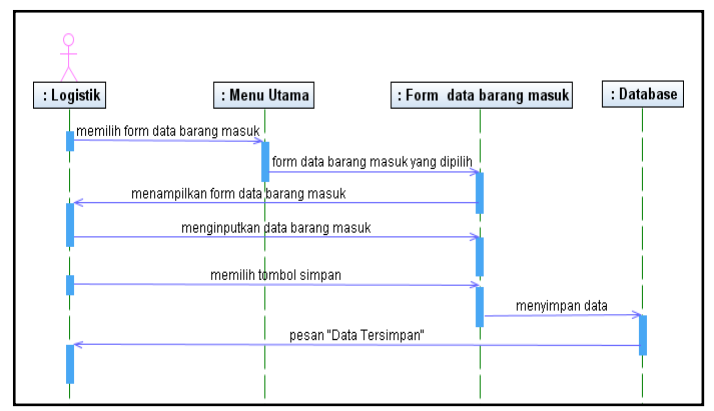

Gambar 12 Sequence DiagramInput Data Barang Masuk 


\subsection{Use Case Diagram Subsistem Distribusi Barang Yang Diusulkan}

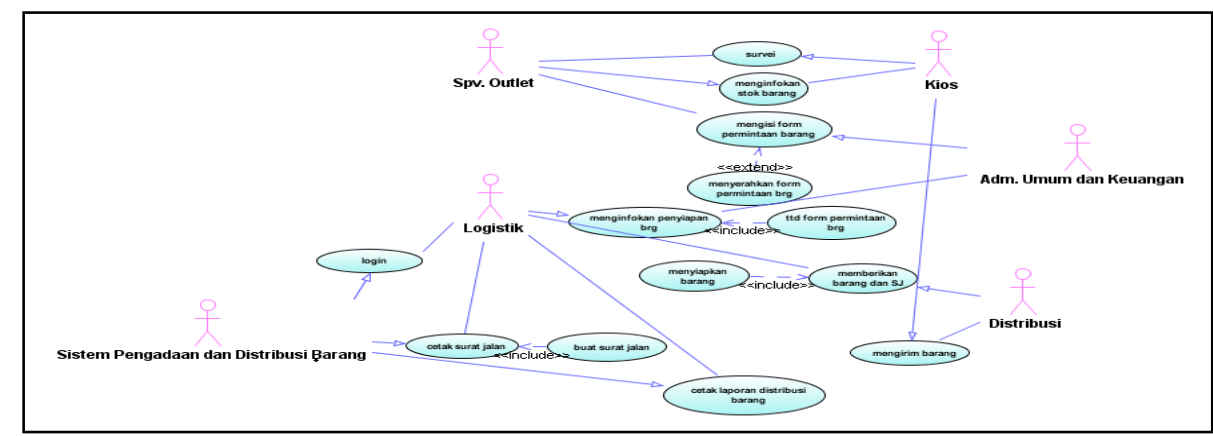

Gambar 13 Use Case Diagram Subsistem Distribusi Barang Yang Diusulkan

\section{KESIMPULAN}

Berdasarkan penjelasan sebelumnya, maka kesimpulan dari penulisan ini adalah :

a. Belum adanya sistem informasi yang mengolah data pengadaan dan distribusi barang pada Master Fried Chicken And Burger Bandar Lampung, sehingga masih sering terjadi keterlambatan bahkan penumpukan dalam proses pengadaan dan distribusi barang, maka dibutuhkan sistem yang dapat membantu pengolahan data pengadaan dan distribusi barang agar dapat memudahkan pihak Master Fried Chicken And Burger Bandar Lampung.

b. Dengan adanya sistempengadaan dan distribusi barang pada Master Fried Chicken And Burger Bandar Lampung dapat memberikan kemudahan kepada bagian Administrasi Umum dalam kegiatan pembuatan laporan pengadaan dan distribusi barang.

\section{DAFTAR PUSTAKA}

Andi. 2008. Membuat Aplikasi Database Dengan Java dan MYSQL. Yogyakarta . Andi Offset

DJ-CTC. 2011. Modul Pelatihan Analisis Perancangan Sistem Informasi. Bandar Lampung: DJ-CTC.

Huda, Miftakhul. 2011. Membuat Aplikasi Mini/Supermarket Dengan Java. Yogjakarta. Kompas Gramedia

Jogianto, H.M. 2005. Analisis dan Desain Sistem Pendekatan Terstruktur Teori dan Praktek Aplikasi Bisnis. Jakarta Andi Offset

Kusrini. 2007. SQL Server 7.0. Jakarta. Gramedia.

Nugroho, Adi. 2005. Rational Rose untuk Pemodelan Berorientasi Objek. Bandung.Informatika.

Sutanta, Edhy. 2004. Sistem Basis Data. Yogyakarta. Graha Ilmu 